\title{
Design of the straw collecting box of the corn harvester
}

\author{
Xiaorong LÜ ${ }^{1,} \mathrm{a}^{*}$, Xiaolian LÜ \\ 1 College of Machinery \& Electronics, Sichuan Agricultural University, Ya'an, 625014, China \\ 2 College of Machinery and Electronic Engineering, Chuzhou University, Anhui, 239000, China \\ a Ixrxj2008@163.com, b LxI500@sohu.com
}

Keywords: The collecting straw box, straw recycling, mechanism design, virtual design

Abstract. This paper designs the straw collecting box of the corn harvester, which is used to recover the corn straw. In the process of harvesting the corn harvester, the device can be able to complete the task of straw collection, which can effectively reduce the labor intensity of the straw recycling, improve the efficiency and quality of straw recycling. Through the virtual prototyping technology, the design of the whole structure of the straw collecting box is completed.

\section{Introduction}

The straw collecting box is an important working part of the grain harvesting machine in the harvest process. It is usually installed in the tail of the harvester to collect the grain crop straw [1, 2]. But now most of the grain harvest machinery after harvest, which is the straw and other debris directly even scatters in the fields, which is very bad for the recovery of straw [1,2,3]. To good of cereal straw recycling, the project is to design a set of the collecting box of the corn harvester, which can better complete grain harvesting machine in the process of harvesting the straw and other debris collection, when the straw collection to a certain weight, set collecting straw box at the bottom of the door and the front door automatically opened, will collect the straw are automatically unloaded on the ground, convenient to pick up the machine to pick up the straw. The straw collecting box can not only reduce the workload of the recycling of straw, but also greatly improve the efficiency and quality of straw recycling.

\section{Structure and working principle}

Design of the whole structure. In this paper, the straw collecting box of the corn harvester is composed of the right side plate, claw disc, long rod, short connecting rod, motor, supporting frame, front door, floor, connecting rod upper arm, arm connecting rod, connecting rod under arm, the left side plate, the rear plate, the horizontal axis, Shaft seat, fixed shaft, torsion spring, etc.. The straw collecting box overall structure diagram is shown in figure 1 (a), (b). 


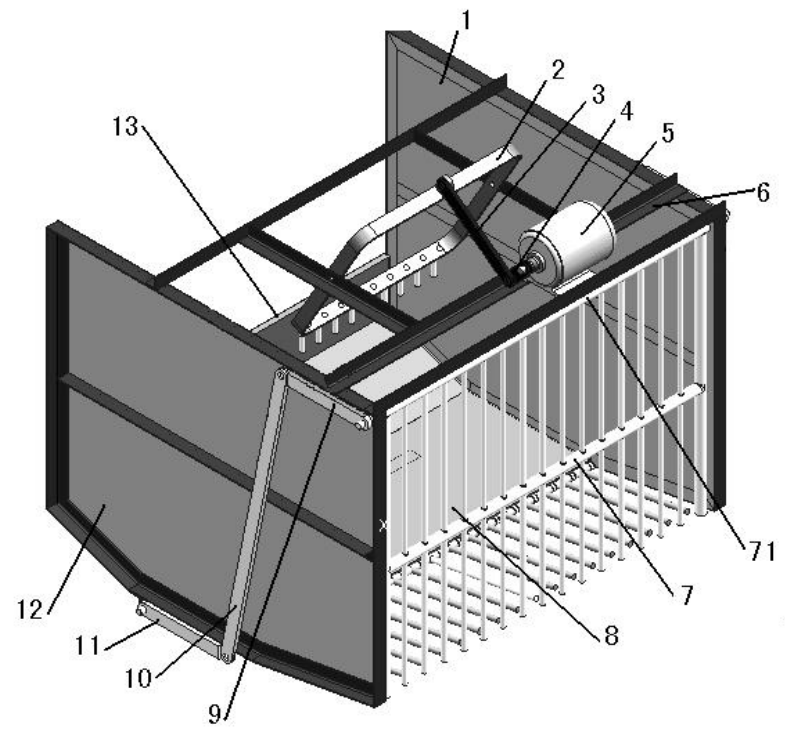

(a)

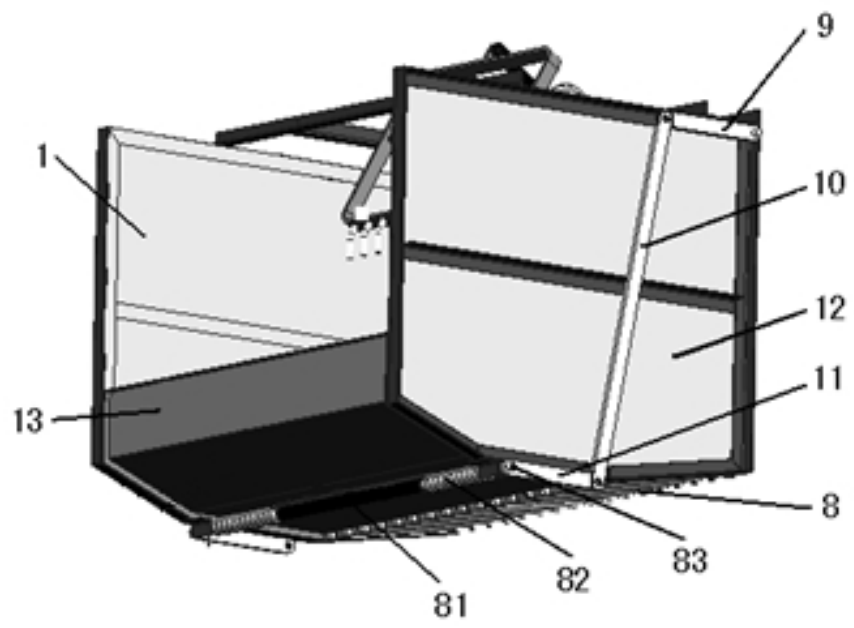

(b)

Fig.1 Structure diagram of the straw collecting box

(a) Front side structure schematic diagram; (b) Rear side structure schematic diagram

1 The right side plate 2 Claw disc 3 long rod 4 short connecting rod 5 motor

6 supporting frame 7 front door 8 floor 9 connecting rod upper arm

10 connecting rod middle arm 11 connecting rod under arm 12 Left side plate 13 rear plate

71 the horizontal axis 81 Shaft seat 82 fixed shaft 83 torsion spring

Working principle. When the corn harvester needs to collect the straw, the straw collecting box can be set up in the back of the corn harvester. Before harvest, open the motor, the motor drives the short connecting rod, the long connecting rod movement, then the long connecting rod drives the claw disc movement, realizes the claw disc to swing.

When the corn harvester into the field, the harvest of corn stalks and other debris were blown to the end of the harvester's tail, and then into the back of the straw stalk. With the harvest, the straw in the collection of more and more accumulation, at this time, the electric motor driven by the claw disc back and forth to swing, the front end of claw disc to push the front and rear of the straw, so that the straw evenly distributed to the entire box. Because the claw lower of the claw disc has the role of compaction, coupled with the gravity of the straw, effectively remove the gap between the straw, expanding the effective volume of the box body. When the straw reaches the specified mass, 
the bottom door is opened by gravity. When the bottom door is opened, the connecting rod under arm is driven to move downwards, so the connecting rod under arm to drive the whole link to move. And the connecting rod upper arm and the horizontal axis are consolidated. Therefore, the connecting rod upper arm drives the horizontal axis counterclockwise rotate, realize the front door around the horizontal axis counter clockwise, the front door was open. When the straw is discharged, the bottom door is closed under the action of the torsion spring restoring force. Through the connecting rod mechanism, the front door around the horizontal axis to rotate clockwise, the front door is closed. The straw of a loading and unloading is completed. Grain harvesting machine in the operation process, the straw handling go round and begin again, until finally complete the task.

\section{Structure characteristics}

Straw collecting box structure is characterized in that, the support frame and a right side plate, a left side plate, a back plate consolidation to form a box body, the front door is hinged with the support frame, bottom door and the rear plate hinged, forming box two movable doors; The supporting frame is provided with a motor and a claw disc; between the motor and the claw disc consists of a short connection rod and the long connecting rod connected to form a connecting rod structure, so as to realize the swinging left and right claw disc; Connecting rod upper arm, connecting rod middle are and connecting rod arm composed of connecting rod mechanism; the connection rod upper arm and the horizontal axis of front door is connected, connecting rod under arm and the fixed shaft of the bottom door is connected, forming interactive agency.

Straw collecting the structure characteristics of the straw box is also reflected in, the front door is composed of a grid structure; horizontal axis of the upper end of the front door, and grid consolidation, and the connecting rod arm connected. The bottom door, the rear part is a flat structure, the front is a grid structure, and the back set shaft seat; The fixed shaft is fixed in the shaft seat, and two ends into the torsion spring and the connecting rod under arm connected; Torsion spring fitted into the fixed shaft ends. One end of the steel wire of the torsion spring is fixed on the fixed base of the supporting frame and can not be moved, while the other end of the steel wire is on the bottom door and can be moved with the bottom door.

\section{Straw collecting box virtual design}

In this paper, the straw collecting box is design through the virtual 3D. Virtual design technology provides a product design environment, optimize the product design process, to research and development of new products provides a strong support. By using the virtual design technology, which can improve the design quality, reduce design errors and manufacturing costs [3, 4]. On the basis of the structure scheme and the main technical parameters of the straw collecting box, the structure of the set of the straw collecting box is designed by using UGNX software. Its main structural design is as follows, such as the structural of the box design (Figure 2), the structure of the claw disc design (Figure 3) and the structure of the connecting rod design (Figure 4).

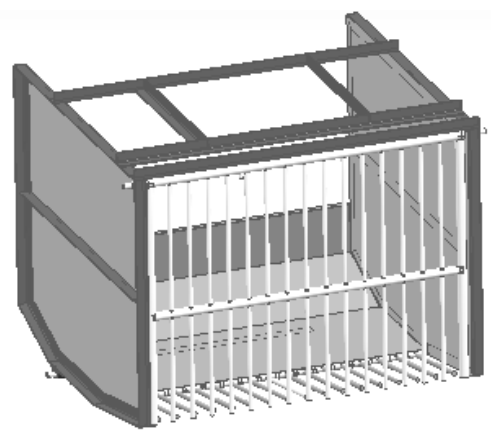

Fig.2 Structure diagram of the box 

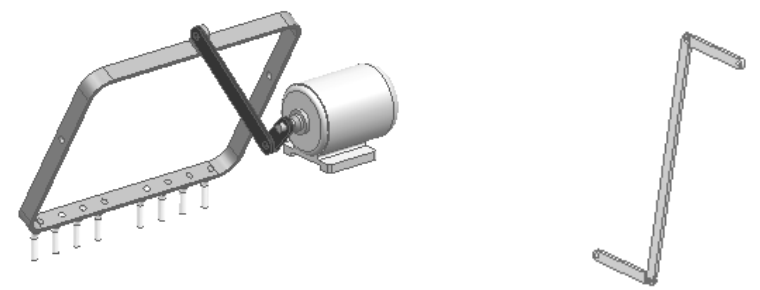

Fig.3 Structure diagram of the claw disc Fig.4 Structure diagram of the connecting rod

Through 3D software UG, the straw collecting box is 3D modeling, assembly, and interference detection between all parts [4]. The results showed that there was no interference between each components, the machine has reasonable structural design. The straw collecting box overall virtual assembly are shown in figure 1 .

\section{Conclusion}

The straw collecting straw box is installed in the back of the corn harvester. The straw is unloaded by the weight of the straw. The size of the straw can be controlled by the torsion spring. In addition to the side wall of the collector box, the bottom door and the front door are composed by the grid, so as to reduce the weight and air permeability of the box. When unloaded, the bottom door and the front door are linked to open to unload the straw. When the straw is removed, the bottom door and the front door are closed by torsion springs. Thus, effectively improve the efficiency and quality of the straw collecting box. The bottom bar is hinged structure, and when the bottom is in contact with the ground, the bottom door is raised and will not cause damage. The set of the grass box adopts the structure of the claw plate connecting rod. It has simple structure, convenient loading and unloading, the effective realization of the claw disc reciprocating motion, so that the uniform distribution of straw in the box body, and the claw plate down, the claw has a compaction effect, thereby effectively saving the effective space of the box. New the straw collecting box has been successfully applied for the national patent of utility model, which provide a new idea to design collecting straw device for the corn harvester.

\section{Acknowledgements}

The Sichuan Province Leaders in Academic and Technical Training Project Funding

\section{Reference}

[1] Ding Weimin. Agricultural Mechanics. Beijing: China Agricultural Press. (2011), In Chinese

[2] Chinese Agricultural Mechanization Sciences Academy. Agricultural Machinery Design Handbook. Beijing: China Agricultural Science and Technology Press. (2007), In Chinese

[3] Chen Zhi, Yang Fangfei. Agricultural machinery digital design technology. Beijing: Science Press. (2015), In Chinese

[4] Lv Xiaorong, Ding Weimin. Agricultural Mechanization Research, No.6 (2013), P.250-252, In Chinese 